\title{
INTERPRETATION OF THE COMMUNICATIVE APPROACH IN THE EDUCATION OF PRIMARY SCHOOL IN AN INCLUSIVE CLASS BY THE PARTICIPANTS OF THE EDUCATIONAL PROCESS (BASED ON THE STUDY OF EDUCATIONAL INSTITUTIONS OF PERM KRAI)
}

(C) 2019

\author{
Kosolapova Larisa Aleksandrovna, doctor of pedagogical sciences, professor of Pedagogy Department \\ Lyskova Guzal Tagirovna, postgraduate student of Pedagogy Department \\ Perm State Humanitarian Pedagogical University (Perm, Russian Federation)
}

\begin{abstract}
The research work deals with the study of the concept of communicative approach in the education of children with disabilities, the study gives the definition of «communication», «competence», «speech activity», «inclusive education». The research attempts with the review of theoretical literature on the problem of the communicative approach in teaching children with disabilities in general education institutions of the Russian Federation. The authors analyze the material of the regulatory framework for the implementation of inclusive education in the Russian Federation, refers to the empirical base of research questionnaires of teaching staff of educational institutions through the prism of the viability of inclusive teaching methods in Perm Krai. The authors point to the shortcomings of the forms of interaction between the teaching staff and children with special needs in the development, conclude that the implementation of the communicative approach in education is the most effective method of interaction within the framework of the inclusive education program in the Russian Federation, provide recommendations for the successful implementation of this approach. The analysis showed that information and communication competence most successfully developed in the work of small groups, with the group use of the case method in the application of the model method of training, especially when using different variations of business games and technologies based on the use of information and communication electronic technologies.

Keywords: communication; situation of communication; disabled child; child with special needs; inclusive education; educational institution; speech activity; Perm Krai; socialization; teaching staff.
\end{abstract}

\section{МЕТОДИКА ИЗУЧЕНИЯ ПОПУЛЯЦИИ В ШКОЛЬНОМ КУРСЕ БИОЛОГИИ}

\author{
Ламехов Юрий Геннадьевич, доктор биологических наук, \\ профессор кафедры общей биологии и физиологии \\ Ламехова Елена Анатольевна, кандидат педагогических наук, \\ доцент кафедры общей биологии и физиологии \\ Южно-Уральский государственный гуманитарно-педагогический университет \\ (2. Челябинск, Российская Федеращчия)
}

\begin{abstract}
Аннотация. В данной статье рассматривается методика изучения популяции в школьном курсе биологии, исходя из особенностей организации процесса обучения в средней общеобразовательной и высшей школе. Понятие «популяция», введенное в биологию еще в начале XX века, не сразу вошло в школьный курс, хотя в настоящий момент оно используется при изучении как частных, так и общебиологических наук. Очевидна связь содержания понятия с генетикой, экологией и синтетической теории эволюции. На основании этого существуют разные трактовки понятия «популяция», взаимно дополняющие друг друга. В статье отмечается необходимость правильности приведения примеров популяций, которые должны подчеркивать состояние изоляции, длительность существования и возможность скрещивания между организмами в пределах популяции. Также отмечается значение использования схематического изображения популяции и ее примеров. Схематизация заключается в отражении двух основных вариантов распределения организмов в популяции и в обсуждении роли рассмотренных вариантов в поддержании существования популяции. Вместе с тем рассмотренная соподчиненность в популяции также важна в обеспечении эволюционного процесса. Формирование понятия «популяция» опирается на вводимый в курс школьной биологии закон Харди-Вайнберга, который до недавнего времени изучался только в вузовском курсе генетики. Но полноценное осознание популяции возможно только при рассмотрении этого закона, характеризующего генетическую структуру популяций. Предлагаемый подход опирается на эколого-эволюционный подход к изучению основных общебиологических понятий в школьном и вузовском курсе.

Ключевые слова: методика обучения биологии; общебиологические понятия; средняя общеобразовательная школа; высшая школа; популяция; генетика; экология; закон Харди-Вайнберга; схематизация; эволюционный процесс; междисциплинарный подход; биологическое разнообразие; популяция щуки обыкновенной; элементарная эволюционная структура.
\end{abstract}

Развитие биологии в XIX-XX веках сопровождалось выдвижением новых гипотез и формулировкой новых теоретических обобщений. Названная особенность в развитии биологии, как и других наук, реализовывалась при появлении и последующем развитии частных и общих биологических понятий. Одним из общебиологических понятий, получивших широкое признание и распространение, является понятие «популяция», предложенное еще в начале XX века. Анализ современного состояния биологической науки 
убеждает в том, что названное понятие применяется при изучении как частных, так и общебиологических наук, что позволяет с большей степенью достоверности описывать биологические процессы, протекающие на разных уровнях организации жизни. Широкое применение понятия «популяция» привело к разнообразию вариантов характеристики названной совокупности организмов и повлияло на методические подходы при изучении популяции как особой совокупности организмов. По мнению А.С. Северцова [1], совокупность организмов, называемая популяцией, представляет собой отвлеченное понятие. Несмотря на такой вариант отношения к популяции, изучение ее характеристик играет важную роль при изучении биологии растений, животных и описании биологического разнообразия [2-4]. Учет популяционной структуры и роли популяций в эволюционном процессе имеет особое значение при изучении такого эволюционного процесса, как антропогенез [5; 6].

Анализ научной и учебной литературы позволяет прийти к выводу о том, что в настоящее время понятие «популяция» рассматривается с позиций генетики, экологии и синтетической теории эволюции. При таком подходе не формируется целостное представление о структуре популяции и ее параметрах, важных с экологической и эволюционной точек зрения. Выходом из сложившей ситуации может быть использование определения популяции, сформулированное с точки зрения синтетической теории эволюции [7]. При изучении теории эволюции и популяции, как одной из тем в пределах этой учебной дисциплины, возможна реализация междисциплинарного подхода [8]. Формирование понятия популяция может осуществляться при проведении лабораторных работ или в ходе демонстрации объектов животного или растительного характера [9].

Целью нашей работы является разработка методики изучения популяции в школьном курсе биологии.

Опыт работы по проведению занятий, в ходе которых изучается популяция, позволяет прийти к некоторым обобщениям, лежащим в основе методически грамотного и научно обоснованного изучения популяции как элементарной эволюционной структуры. Проведение занятия по указанной теме возможно при учете содержания фрагмента программы, позволяющей провести отбор содержания по теме «Популяция». Ниже приведен перечень вопросов, рекомендуемых для изучения.

- Определения популяции с позиций современной экологии, генетики и синтетической теории эволюции.

- Основные характеристики, лежащие в основе синтетического определения популяции.

- Значение критериев выделения популяции в эволюционном процессе.

- Примеры популяций из мира растений и животных.

- Примеры популяций в пределах вида человек разумный.

- Современные подходы, описывающие структуру популяций.

- Критерии выделения группировок особей, существующих в пределах популяций (на примере растений или животных).
- Основные экологические характеристики популяции: популяционный ареал, численность особей, половой состав и возрастной состав популяции.

- Значение экологических характеристик популяции в протекании эволюционного процесса.

- Эволюционно-генетические характеристик популяции: норма реакции генотипа, частоты генов, генетическая гетерогенность и внутрипопуляционный полиморфизм.

Современный вариант определения популяции с точки зрения синтетической теории эволюции приведен как в научной [10], так и в учебной литературе [11-13]. При знакомстве с различными вариантами трактовок определения необходимо вычленить три положения, определяющие синтетический характер определения: длительность существования, изолированность и проявление панмиксии между организмами в пределах одной популяции. Формулировка определения популяции должна быть дополнена ее схематическим изображением и примерами. При схематическом изображении популяции рекомендуется в пределах условно очерченного видового ареала выделить два основных варианта распределения организмов: в виде островов и сгущений. С использованием представленной схемы уместно обсудить роль основных характеристик популяции в поддержании ее существования и обеспечения участия в эволюционном процессе.

Особое значение имеет правильность приведения примеров популяций. Конкретные примеры должны выделяться при учете изоляции, длительности существования и свободного скрещивания между организмами в пределах популяции. При проведении занятия мы используем примеры следующих группировок, существующих на территории нашей области и соответствующих статусу популяции. Это популяция сосны обыкновенной Челябинского бора и популяция элодеи канадской Шершневского водохранилища. При выделении популяций в пределах видов у животных необходимо учитывать, что высокая подвижность животных выступает в качестве причины, нарушающей изоляцию, и препятствует формированию популяций. Убедительные примеры популяций у животных можно привести по отношению к обитателям водной среды, границы которой выступают в качестве преграды для распространения животных. Для нашего региона удачными можно считать следующие примеры: популяция щуки обыкновенной в озере Чебаркуль или популяция перловицы обыкновенной, обитающей в Первом озере. К числу самых ярко выраженных популяций в пределах вида человек разумный относятся большие географические расы.

Выделение популяций в пределах видов живых организмов и их существование в пределах эволюционно значимого интервала времени связано не только с подвижностью живых организмов, но и с особенностями среды обитания. В силу этого по отношению к подвижным животным популяцию трудно выделить в природной обстановке. Это создает определенные трудности при организации изучения популяции как группировки особей в пределах вида. Затруднения вызывает выделение популяций для видов птиц, что обусловлено их высокой подвижностью. При использовании примеров популяций, 
формирующихся на территории видового ареала у птиц, рекомендуется выбирать виды птиц с оседлым образом жизни. Типичными примерами таких популяций являются группы сизых голубей, обитающие на территории населенного пункта.

Выбранные примеры совокупностей организмов обсуждаются, и в ходе обсуждения необходимо доказать, что эти совокупности существуют длительно, в состоянии изоляции и при проявлении панмиксии в пределах популяции. Длительность существования группировки особей необходима, так как в течение большого интервала времени с большей вероятностью возникают адаптации организмов популяции к условиям обитания. Панмиксия выступает в качестве условия, обеспечивающего половое размножение организмов, а значит, и поддержание необходимой численности, что с экологической точки зрения выступает в качестве гомеостаза популяции.

Ocобое внимание желательно уделить проявлению изоляции, роль которой связана с несколькими выделяемыми в настоящее время формами [14]. Для существования популяции необходимо проявление действия биотопической изоляции. Эта форма сохраняет индивидуальность сформировавшихся популяций, но не является механизмом, который обеспечивает абсолютную изолированность между популяциями на территории видового ареала.

По-прежнему спорным остается вопрос о статусе колоний, которые формируются в пределах видового ареала у некоторых видов птиц. В литературе приводятся сведения о роли условий среды обитания, которые влияют на распределение птиц даже на небольших по площади территориях [15], что приводит к формированию колониальных поселений в пределах вида у птиц. В настоящее время опубликованы результаты изучения пространственно-временной структуры моновидовых и поливидовых колоний птиц $[16 ; 17]$, что позволяет отнести колониальные поселения у птиц к варианту популяций.

Реальность существования популяции в пределах вида позволяет описывать ее структуру, учитывая наличие совокупностей организмов и их взаимодействие. Такой подход к описанию структуры представлен в учебной литературе [1]. Предлагается в пределах популяции выделять следующую последовательность группировок особей: семья, микропопуляция, локальная популяция, экологическая популяция и географическая популяция. При изучении этих совокупностей особей необходимо назвать критерий их выделения и привести примеры совокупностей организмов. Эти сведения рекомендуется представить в форме таблицы (табл. 1).

Описывая названные группировки особей в пределах популяции, необходимо подчеркнуть связь между ними и возможность изменения их статуса в процессе эволюционных преобразований.

Изучение популяции связано с усвоением материала по экологическим и эволюционно-генетическим характеристикам популяции. В учебной литературе [1; 10-12] приведены варианты описания основных характеристик популяции как единицы вида и эволюции. Изучение этих характеристик рекомендуется осуществлять при соблюдении следующей последовательности: площадь популяционного ареала, численность особей, возрастной состав, половой состав популяции, норма реакции генотипа, генетическая гетерогенность организмов в популяции, частоты генов и генотипов, а также внутрипопуляционный полиморфизм. Описание каждой из названных характеристик должно сопровождаться формулировкой определения, примерами из мира растений, животных и по отношению к виду человек разумный, анализом причинно-следственных связей между описываемой характеристикой популяции и условиями окружающей среды. Особое значение при изучении параметров популяции играет выяснение эволюционной роли как экологических, так и эволюционно-генетических характеристик.

В приведенной ниже таблице описано эволюционное значение экологических характеристик популяции (табл. 2).

таблица 1 - Совокупности особей, выделяемые в пределах популяции

\begin{tabular}{|c|c|c|}
\hline $\begin{array}{c}\text { Название совокупности } \\
\text { особей, выделяемых } \\
\text { в пределах популяции } \\
\end{array}$ & $\begin{array}{l}\text { Критерии выделения } \\
\text { группировок особей }\end{array}$ & Примеры \\
\hline 1. Семья & Высокая степень родства & $\begin{array}{l}\text { Гарем морских котиков. } \\
\text { Прайд львов. } \\
\text { Семьи приматов }\end{array}$ \\
\hline $\begin{array}{l}\text { 2. Микропопуляция } \\
\text { (колония) }\end{array}$ & $\begin{array}{l}\text { Размножение на одной терри- } \\
\text { тории при высокой плотности } \\
\text { размещения }\end{array}$ & $\begin{array}{l}\text { Колонии озерных чаек. } \\
\text { Колонии грачей }\end{array}$ \\
\hline 3. Локальная популяция & $\begin{array}{l}\text { Размещение особей } \\
\text { на небольшой территории } \\
\text { с однородными условиями }\end{array}$ & $\begin{array}{l}\text { Микрогруппировки земляники зеленой в березня- } \\
\text { ке, растущие у оснований деревьев и на открытых } \\
\text { местах. } \\
\text { Одна стая речного окуня озера Смолино. } \\
\text { Колонии черных стрижей городского парка } \\
\text { г. Челябинска }\end{array}$ \\
\hline $\begin{array}{l}\text { 4. Экологическая } \\
\text { популяция }\end{array}$ & $\begin{array}{l}\text { Приуроченность } \\
\text { к конкретным экосистемам }\end{array}$ & $\begin{array}{l}\text { Все особи ели европейской в монодоминантных } \\
\text { лесах Челябинской области. } \\
\text { Все стаи речного окуня озера Смолино }\end{array}$ \\
\hline $\begin{array}{l}\text { 5. Географическая } \\
\text { популяция (подвид) }\end{array}$ & $\begin{array}{l}\text { Обитание на территории } \\
\text { с однородными условиями } \\
\text { при сохранении относитель- } \\
\text { ной изоляции }\end{array}$ & $\begin{array}{l}\text { Лиственница даурская: западная и восточная расы. } \\
\text { Тундровая и степная популяция мыши-полевки }\end{array}$ \\
\hline
\end{tabular}


Ламехов Ю.Г., Ламехова Е.А.

Методика изучения популяции в школьном курсе биологии

13.00.00 - педагогические науки

Таблица 2 - Экологические характеристики популяции и их роль в эволюции

\begin{tabular}{|c|c|c|}
\hline $\begin{array}{l}\text { № } \\
\Pi / \Pi\end{array}$ & $\begin{array}{l}\text { Название } \\
\text { экологической харак- } \\
\text { теристики популяции }\end{array}$ & $\begin{array}{c}\text { Значение экологической характеристики популяции } \\
\text { в протекании эволюционного процесса }\end{array}$ \\
\hline 1 & $\begin{array}{l}\text { Площадь популяцион- } \\
\text { ного ареала }\end{array}$ & $\begin{array}{l}\text { Увеличение площади популяционного ареала является доказательством } \\
\text { повышения уровня приспособленности популяции к условиям среды обитания }\end{array}$ \\
\hline 2 & $\begin{array}{l}\text { Численность особей } \\
\text { в популяции }\end{array}$ & $\begin{array}{l}\text { Динамика численности особей в популяции приводит к следующим эволюци- } \\
\text { онно значимым результатам: } \\
\text { - изменяются частоты генов, генотипов и фенотипов; } \\
\text { - создается материал для действия естественного отбора; } \\
\text { - изменяется направление действия естественного отбора в соответствии } \\
\text { с условиями окружающей среды; } \\
\text { - численность особей в популяции является предпосылкой адаптивных преоб- } \\
\text { разований в популяции. }\end{array}$ \\
\hline 3 & Половой состав & $\begin{array}{l}\text { Оптимальное соотношение полов в популяции обеспечивает сохранение чис- } \\
\text { ленности, что приводит к следующим результатам: } \\
\text { - является условием для проявления гомеостаза; } \\
\text { - создается материал для действия естественного отбора. }\end{array}$ \\
\hline 4 & Возрастной состав & $\begin{array}{l}\text { Эволюционно перспективными являются популяции, в которых преобладают } \\
\text { молодые организмы. Наличие в популяции достаточного количества молодых } \\
\text { особей является условием для увеличения численности организмов в популя- } \\
\text { ции и поддержания ее оптимальной численности. При достаточном количестве } \\
\text { организмов в популяции эффективно срабатывает естественный отбор, как ве- } \\
\text { дущий фактор эволюции, приводящий или к сохранению существующих адап- } \\
\text { таций к среде обитания или к возникновению новых приспособлений группо- } \\
\text { вого характера. }\end{array}$ \\
\hline
\end{tabular}

Особое значение при изучении популяции имеет описание сущности и эволюционной роли эволюционно-генетических характеристик популяции. На этом этапе изучения популяции необходима, как в предыдущем случае, формулировка определения, достаточное количество примеров, раскрывающих сущность эволюционно-генетического свойства популяции и описание роли названного свойства в протекании эволюционных преобразований.

Норма реакции генотипа, изучение которой начинается в курсе генетики, играет очень важную роль в эволюционном процессе. В учебной литературе [11] приводится эволюционная характеристика нормы реакции и подчеркивается, что этот параметр популяции проявляется по отношению к отдельным признакам организмов, к фенотипу особей определенной группировки, а также по отношению к совокупностям организмов. Широкая трактовка нормы реакции, с одной стороны, затрудняет организацию учебной работы, связанную с ее изучением, а с другой подтверждает особую значимость нормы реакции генотипа в адаптивном преобразовании организмов [18] и их совокупностей. Эволюционное значение нормы реакции связано с тем, что в пределах нормы реакции формируются адаптивные модификации [18].

Значение модификаций в эволюции, с нашей точки зрения, недостаточно подчеркивается при изучении закономерностей эволюционного процесса как в средней общеобразовательной, так и в высшей школе. При изучении эволюционной роли модификаций необходимо подчеркивать следующие положения:

- модификации формируются под влиянием экологических факторов среды через изменение фенов (т.е. признаков) организма;

- модификации проявляются в фенотипе за короткий промежуток времени, что позволяет организму адаптироваться к среде обитания в ходе онтогенеза;
- процесс формирования и проявления модификаций протекает постепенно, что приводит к приспособительным изменениям организмов на каждой стадии онтогенеза;

- модификации являются обратимыми изменениями фенотипа, что принципиально расширяет адаптивные возможности организма;

- модификационная изменчивость носит групповой характер, что повышает эффективность процесса приспособления к экологическим факторам.

Генетическая гетерогенность организмов в популяции с точки зрения механизмов эволюционного процесса, признаваемых в синтетической теории эволюции, является предпосылкой действия естественного отбора. При описании роли этого свойства популяции важно установление причинно-следственных связей между генетическими, экологическими и эволюционными процессами. Среди причин генетического характера выделяют две основные причины: мутационный процесс и рекомбинацию вещества наследственности. Экологические факторы среды при определенной интенсивности действия также могут приводить к изменениям наследственности, что будет приводить к повышению степени гетерогенности организмов в популяции.

Оптимальным вариантом условий, необходимых для успешного изучения роли частот генов в эволюции популяций, является знание учащимися сущности закона Харди-Вайнберга, позволяющего описывать генетическую структуру популяции. Объективное описание генетической структуры популяции опирается на вычисление частот генов, которые позволяют провести вычисление долей гомозигот и гетерозигот, а вместе с этим определить количество организмов, являющихся, например, гетерозиготами. Получив названные сведения, можно перейти к описанию роли генетической структуры популяции в микроэволюционном процессе. Для получения ин- 
формации эволюционного характера необходимо проанализировать возможные ситуации, в ходе которых изменяются частоты генов в популяции. С нашей точки зрения, на этом этапе изучения материала учащимся предоставляется информация о частотах генов в популяции и характере ее изменения. В качестве примера можно использовать данные об изменении частот генов, приведенные в таблице (табл. 3).

Таблица 3 - Сезонные изменения частот генов в изучаемой популяции

\begin{tabular}{|l|c|c|}
\hline $\begin{array}{c}\text { Обозначение } \\
\text { гена }\end{array}$ & $\begin{array}{c}\text { Время } \\
\text { года }\end{array}$ & $\begin{array}{c}\text { Частота встречаемости ге- } \\
\text { на в изучаемой популяции }\end{array}$ \\
\hline Доминант- & Весна & 0,2 \\
ный ген - $\mathrm{p}$ & Осень & 0,7 \\
\hline Рецессивный & Весна & 0,8 \\
ген $-\mathrm{q}$ & Осень & 0,3 \\
\hline
\end{tabular}

Приведенные в таблице данные о частотах генов, соответствуют частотам, проявляющимся в панмиктических популяциях. По закону Харди-Вайнберга сумма частот доминантного и рецессивного генов в популяции со свободным скрещиванием организмов должна быть равна единице. В ходе адаптивных преобразований на фоне изменяющихся условий окружающей среды происходит изменение частот генов. Если частота гена увеличивается, значит, данный ген распространяется в пределах популяции и повышает ее приспособленность к условиям среды обитания. Данные по частотам генов, приведенные в таблице, позволяют сделать вывод о том, что частота доминантного гена увеличилась с 0,2 до 0,7 , а частота рецессивного гена уменьшилась с 0,8 до 0,3 . Приведенные в таблице данные позволяют прийти к следующему выводу: повышение уровня приспособленности популяции при сезонной смене условий окружающей среды происходит за счет доминантного гена. При изменении частот генов в популяции изменяются частоты генотипов и фенотипов. Процесс изменения генотипической структуры популяции будет в целом обеспечивать ее адаптивное преобразование.

Основным эволюционно-генетическим свойством популяции является внутрипопуляционный полиморфизм, описанный в научной и учебной литератуpe $[1 ; 11-14]$. Значение этой характеристики в изучении популяций раскрывают следующие положения:

- внутрипопуляционный полиморфизм является доказательством адаптивного характера структуры популяции;

- возникновение внутрипопуляционного полиморфизма доказывает генетическую связь между индивидуальными и групповыми адаптациями, формирующимися в процессе микроэволюции;

- на примере проявлений полиморфизма, существующего в пределах популяции, анализируются начальные стадии процесса видообразования.

Эффективное усвоение учебного материала при изучении темы «Популяция», как и других тем курса биологии, зависит от методически грамотного подбора наглядных пособий. К их числу относятся объекты растительного и животного происхождения, имеющие биологические особенности, позволяющие провести демонстрацию проявления основных параметров популяции. Опыт работы в этом направлении убеждает в необходимости использования гербарного материала по такому виду, как тысячелистник обыкновенный (Achillea millefolium L.). В пределах популяции этого вида растения выделяются организмы, отличающиеся по окраске венчика цветков. Выделяются три формы: с красным, розовым и белым венчиками. Они различаются по генотипу. Самыми многочисленными, по нашим наблюдениям, являются формы с розовой окраской венчика, а самая редкая форма - организмы с красной окраской венчика, являющиеся доминантными гомозиготами. Использование гербарных образцов этого вида растения имеет преимущества, связанные, прежде всего, со следующими причинами:

- лепестки цветов не теряют окраску при правильной гербаризации;

- окраска лепестков остается естественной при длительном хранении оформленных гербарных образцов.

Использование тысячелистника обыкновенного позволяет убедительно продемонстрировать внутрипопуляционный полиморфизм на примере этого вида растения.

Среди животных объектов удобно использовать насекомых, экземпляры которых можно оформить в виде энтомологической коллекции. Незаменимыми вариантами наглядных пособий являются два вида, относящиеся к отряду жуки: двуточечная божья коровка (Adalia bipunctata L.) и колорадский жук (Leptinotarsa decemlineata (Say, 1824)). У первого вида проявляется полиморфизм по окраске тела - в пределах одной популяции выявляются красные и черные формы. При изучении особей колорадского жука, относящихся к одной популяции, выявляются формы, различные по рисунку на грудном отделе тела.

Описание примеров внутрипопуляционного полиморфизма, проявляющегося в пределах вида у насекомых, должно сопровождаться информацией об адаптивной ценности тех различий между организмами, проявление которых относится к полиморфизму.

Использование раздаточного материала может быть организовано в форме проведения лабораторной работы. Особенности проведения лабораторных работ при изучении закономерностей эволюционного процесса описаны в литературе [9; 19]. При изучении внутрипопуляционного полиморфизма возможно проведение лабораторной работы по теме «Изучение полиморфизма колорадского жука по рисунку на грудном отделе тела». Для проведения названной работы достаточно обычного лабораторного оборудования, к которому относятся лупа, пинцет и канцелярские принадлежности. В качестве биологического материала используются зафиксированные особи колорадского жука. При выполнении работы описываются варианты рисунков на грудном отделе тела этого вида насекомых. При подведении итогов выполнения работы рекомендуется ответить, например, на следующие вопросы:

- Какой объем выборки подвергнут описанию?

- Какие варианты имеют максимальную частоту встречаемости, а какие встречаются с минимальной частотой?

- По каким особенностям отличаются варианты рисунков на грудном отделе тела колорадского жука?

- В чем адаптивное значение разнообразия жуков одной популяции по рисунку на грудном отделе тела?

Изучение теоретической части занятия и выполнение практических заданий должно закончиться подведением итогов занятия. В качестве обязательного элемента подведения итогов должно быть об- 
суждение ответа на вопрос «Почему популяция является элементарной, т.е. неделимой эволюционной структурой»? Ответ на сформулированный вопрос является результатом длительного развития эволюционной биологии, и его современная формулировка включает следующие положения:

- популяция эволюционно неделима, а значит элементарна;

- в популяции возникает групповая наследственная изменчивость, являющаяся основой для формирования групповых адаптаций;

- в популяции протекает элементарное эволюционное явление: длительное направленное изменение генофонда популяции.

Особое значение в описании популяции и ее роли в эволюции имеет последнее положение. При его анализе необходимо подчеркнуть, что изменение генофонда популяции должно быть связано, прежде всего, с накоплением мутаций, повышающих уровень приспособленности организмов популяции к среде обитания.

Теоретическое изучение популяции, ее структуры и характеристик позволяет грамотно решать практические задачи, стоящие в настоящее время перед человечеством. Практическое применение совокупности знаний о популяциях должно опираться на эволюционно-экологическое мышление. В этом случае реальным может стать решение следующих задач:

- стабилизация состояния существующих природных ресурсов;

- организация воспроизводства природных ресурсов;

- создание управляемых высокопродуктивных биогеоценозов;

- организация адаптивно-ландшафтного землепользования;

- разработка и создание замкнутых экологических систем различного уровня [20].

\section{Вывод}

Таким образом, современный уровень изучения популяции в биологии как в средней общеобразовательной, так и в высшей школе связан с реализацией двух ведущих методологических конструктов, возникших в XX веке, - идеи развития и организации. Названные конструкты с точки зрения современной методологии биологии [20] реализуются в форме эволюционного и экологического подходов, синтез которых может стать основой формирования нового эколого-эволюционного подхода.

\section{Список литературы:}

1. Северцов А.С. Основы теории эволюции. М.: МГУ, 1987. 319 с.

2. Ламехова Е.А., Ламехов Ю.Г. Современные представления о видовом разнообразии на уроках ботаники // Инновационная наука. 2016. № 5-3 (17). С. 139-145.

3. Уткина Т.В., Ламехова Е.А., Ламехов Ю.Г. К вопросу о методике изучения биологического разнообразия в средней общеобразовательной школе // Инновационная наука. 2016. № 2-3. С. 203-208.

4. Уткина Т.В., Ламехов Ю.Г., Ламехова Е.А. Биологическое разнообразие Челябинской области: уч.метод. пособие. Челябинск: ЧИППКРО, 2015. 319 с.

5. Тюмасева 3.И., Ламехов Ю.Г., Виноградов Н.Б. Современные проблемы происхождения человека - в биологическом образовании школьников. Челябинск: ИУУ, $1992.95 \mathrm{c.}$

6. Тюмасева 3.И., Ламехов Ю.Г. Вопросы антропологии в биологическом образовании школьников. Челябинск: ИУУ, 1988. 50 с.

7. Ламехов Ю.Г. Формирование понятия «популяция» в курсе «Общая биология» // Методология и методика формирования научных понятий у учащихся школ и студентов вузов: тезисы докладов междунар. науч.-практ. конф. Ч. 2 / отв. ред. А.В. Усова. Челябинск: Изд-во Факел, 1995. С. 13-14.

8. Ламехов Ю.Г. Междисциплинарный подход при изучении теории эволюции в средней и высшей школе // Междисциплинарный подход при изучении теории эволюции в средней и высшей школе // Междисциплинарность науки как фактор инновационного развития: сб. статей междунар. науч.-практ. конф. / отв. ред. А.А. Сукиасян. Уфа: Аэтерна, 2017. С. 146-149.

9. Ламехова Е.А., Ламехов Ю.Г. Методика проведения лабораторных занятий по теории эволюции при изучении общей биологии в средней школе // Актуальные проблемы методики преподавания биологии, химии и экологии в школе и вузе: мат-лы всеpoc. с междунар. участием науч.-практ. конф. / отв. ред. В.В. Пасечник. М.: МГОУ, 2017. С. 85-87.

10. Яблоков А.В. Популяционная биология. М.: Высшая школа, 1987. 303 с.

11. Яблоков А.В. Эволюционное учение. М.: Высшая школа, 1998. 335 с.

12. Георгиевский А.Б. Дарвинизм. М.: Просвещение, $1985.271 \mathrm{c}$.

13. Воронцов Н.Н., Сухорукова Л.Н. Эволюция органического мира. М.: Наука, 1996. 256 с.

14. Майр Э. Популяции, виды и эволюция. М.: Мир, 1974. 460 с.

15. Ламехов Ю.Г., Чухарева И.П. Особенности видового состава и распределения птиц на озере Курлады // Вестник Челябинского государственного педагогического университета. 2001. № 4. С. 163.

16. Ламехов Ю.Г. Пространственно-временная структура колоний птиц и биологические аспекты раннего онтогенеза: автореф. ... д-ра биол. наук. Казань, 2010. 59 с.

17. Ламехов Ю.Г. Последовательность формирования пространственно-временной структуры поливидовых и моновидовых колоний птиц // Вестник ЧГПУ. 2013. № 7. С. 259-266.

18. Ламехова Е.А. Формирование понятия «адаптация» у будущих учителей при изучении растений и растительности // Адаптация биологических систем к естественным и экстремальным факторам среды: мат-лы VI междунар. науч.-практ. конф. / отв. ред. Д.3. Шибкова. Челябинск: Изд-во ЮУрГГПУ, 2016. C. $440-443$.

19. Ламехов Ю.Г. Значение лабораторных занятий по теории эволюции для профессиональной подготовки будущих учителей биологии // Проблемы и перспективы развития методики обучения биологии в период перехода педагогического образования на многоуровневую подготовку: мат-лы IV всерос. науч.-практ. конф. / отв. ред. В.В. Латюшин. Челябинск: Изд-во Челяб. гос. пед. ун-та, 2008. С. 46-48.

20. Лисеев И.К. Новые методологические ориентации в современной философии биологии // Методология биологии: новые идеи / отв. ред. О.Е. Баксанский. М.: Эдиториал УРСС, 2001. С. 21-32. 


\section{METHODS OF POPULATION STUDY IN A BIOLOGY COURSE AT SCHOOL}

(C) 2019

Lamekhov Yury Gennadyevich, doctor of biological sciences, professor of General Biology and Physiology Department

Lamekhova Elena Anatolyevna, candidate of pedagogical sciences, associate professor of General Biology and Physiology Department

South Ural State Humanitarian Pedagogical University (Chelyabinsk, Russian Federation)

Abstract. This paper discusses methods of population study in a Biology course at school based on characteristics of educational process organization at secondary and high school. The concept of «population», introduced in biology at the beginning of the XX century, was not immediately included in the school course, although at the moment it is used in the study of both private and general biological sciences. The connection of the concept content with genetics, ecology and synthetic theory of evolution is obvious. On the basis of this, there are different interpretations of the «population» concept, mutually complementing each other. The paper states that it is necessary to give correct examples of populations that should emphasize the state of isolation, duration of existence and the possibility of crossing between organisms within a population. The importance of using a schematic representation of populations and its examples is also noted. A schematic representation is a reflection of two basic variants of organism's distribution in the population and discussion of the role of these variants in the maintenance of the population existence. However, the considered subordination in the population is also important in ensuring the evolutionary process. The development of the population concept is based on the Hardy-Weinberg's law introduced in a Biology course at school, which until recently was only studied at the University course of Genetics. But full awareness of the population is possible only when considering this law, which characterizes the genetic structure of populations. The proposed approach is based on the ecological-evolutionary approach to the study of basic general biological concepts in school and University courses.

Keywords: methods of concepts study; general biological concepts; secondary school; high school; population; genetics; ecology; law; Hardy-Weinberg; schematic representation; evolutionary process; multidisciplinary approach; biological diversity; population of common pike; elementary evolutionary structure.

УДК 378.14

DOI 10.24411/2309-4370-2019-11310

Статья поступила в редакцию 20.01.2019

\section{ПЕДАГОГИЧЕСКИЕ ПУТИ РАЗВИТИЯ ПРОФЕССИОНАЛЬНОГО ОПЫТА ДЕЯТЕЛЬНОСТИ В КРИЗИСНЫХ СИТУАЦИЯХ У МАГИСТРАНТОВ ВОЕННОГО ВУЗА}

(C) 2019

Малашенко Леонид Иванович, старший научный сотрудник военного научно-исследовательского центра Национальный университет обороны имени Первого Президента Республики Казахстан (2. Астана, Республика Казахстан)

Аннотация. Актуализируется роль профессионального опыта в подготовке военных специалистов к деятельности в современных условиях, сопряжённых с возникновением и развитием кризисных ситуаций, пронизывающих фактически все сферы жизни общества. Совершенно очевидно, что без профессионально подготовленных, квалифицированных и опытных защитников немыслимо существование любого государства. Это повышает интерес к проблеме развития профессионального опыта офицеров как важного компонента готовности к эффективным действиям антикризисной направленности. В работе показаны методологические подходы к исследованию процесса развития опыта магистрантов - офицеров, обучающихся в военном вузе второго уровня высшего профессионального образования (магистратура). На основе анализа научных трудов в области подготовки военных кадров даётся определение профессиональной готовности военного специалиста. Рассмотрены отличительные особенности развития профессионального опыта офицера. В качестве решения обозначенной проблемы определены основные пути развития профессионального опыта деятельности в кризисных ситуациях у магистрантов военного вуза, в которых совмещается теория с практикой и исследовательской деятельностью, применение международного опыта и опыта ветеранов войн и военных конфликтов, педагогическая поддержка обучаемых с ценностным наполнением содержания образования, дифференциация обучения с особой позицией преподавательского состава, с проявлением особого внимания к формированию опыта у магистратов военного вуза.

Ключевые слова: профессиональный опыт; профессиональная деятельность; профессиональная готовность; профессиональная компетентность; этнокультурная компетентность; военно-профессиональное образование; профессионально-ценностная ориентация; кризисная ситуация; педагогический путь; педагогический поиск; исследовательский путь; интернациональный воинский коллектив; дифференцированный подход; позиция профессорско-преподавательского состава; миссия военного специалиста; магистрант военного вуза; национальный университет обороны; национальная безопасность; военная безопасность; коалиция государств; Организация Договора о коллективной безопасности.

Введение (постановка проблемы и цели исследования)

В современных условиях объективной кризисной реальности, когда ранее отлаженные механизмы за- щиты от потенциальных угроз повсеместно дают сбои, государства всё чаще объединяются в коалиции и решают вопросы обеспечения своей безопасности на коллективной основе. В России и Казах- 